\title{
Chinese Herbal Medicine as a Potential Treatment of Abdominal Aortic Aneurysm
}

\author{
Sai Wang Seto ${ }^{1 *}$, Dennis Chang ${ }^{1}$, Hosen Kiat ${ }^{2,3,4}$, Ning Wang ${ }^{1,5,6,7}$ and Alan Bensoussan ${ }^{1}$ \\ ${ }^{1}$ NICM Health Research Institute, Western Sydney University, Penrith, Australia, ${ }^{2}$ Faculty of Medicine, University of New \\ South Wales, Sydney, Australia, ${ }^{3}$ School of Medicine, Western Sydney University, Penrith, Australia, ${ }^{4}$ Faculty of Medicine \\ and Health Sciences, Macquarie University, Sydney, Australia, ${ }^{5}$ Key Laboratory of Xin'an Medicine, Ministry of Education, \\ Hefei, China, ${ }^{6}$ College of Pharmacy, Anhui University of Chinese Medicine, Hefei, China, ${ }^{7}$ Institute for Pharmacodynamics \\ and Safety Evaluation of Chinese Medicine, Anhui University of Chinese Medicine, Hefei, China
}

\section{OPEN ACCESS}

Edited by:

Giovanni Esposito,

University of Naples Federico II, Italy

Reviewed by:

Xiaoqiang Tang,

West China Second University Hospital of Sichuan University, China Joshua D. Hutcheson,

Florida International University,

United States

*Correspondence:

Sai Wang Seto

s.seto@westernsydney.edu.au

Specialty section:

This article was submitted to

Atherosclerosis and

Vascular Medicine,

a section of the journal

Frontiers in Cardiovascular Medicine

Received: 20 December 2017

Accepted: 20 March 2018

Published: 20 April 2018

Citation:

Seto SW, Chang D, Kiat H, Wang N and Bensoussan $A$

(2018) Chinese Herbal Medicine as a

Potential Treatment of Abdominal Aortic Aneurysm.

Front. Cardiovasc. Med. 5:33. doi: 10.3389/fcvm.2018.00033
Abdominal aortic aneurysm (AAA) is an irreversible condition where the abdominal aorta is dilated leading to potentially fatal consequence of aortic rupture. Multiple mechanisms are involved in the development and progression of AAA, including chronic inflammation, oxidative stress, vascular smooth muscle (VSMC) apoptosis, immune cell infiltration and extracellular matrix (ECM) degradation. Currently surgical therapies, including minimally invasive endovascular aneurysm repair (EVAR), are the only viable interventions for AAAs. However, these treatments are not appropriate for the majority of AAAs, which measure $<50 \mathrm{~mm}$. Substantial effort has been invested to identify and develop pharmaceutical treatments such as statins and doxycycline for this potentially lethal condition but these interventions failed to offer a cure or to retard the progression of AAA. Chinese herbal medicine (CHM) has been used for the management of cardiovascular diseases for thousands of years in China and other Asian countries. The unique multi-component and multi-target property of $\mathrm{CHMs}$ makes it a potentially ideal therapy for multifactorial diseases such as AAA. In this review, we review the current scientific evidence to support the use of $\mathrm{CHMs}$ for the treatment of AAA. Mechanisms of action underlying the effects of CHMs on AAA are also discussed.

Keywords: Chinese herbal medicine, abdominal aortic aneurysm, vascular biology and disease, atherosclerosis, inflammation mediators, oxidative stress

\section{INTRODUCTION}

Abdominal aortic aneurysm (AAA) is an irreversible condition where the abdominal aorta is dilated with a diameter of at least $30 \mathrm{~mm}$ in an adult. The risk factors include male gender, age $>75$ years, pervious vascular disease, hypertension, smoking, family history and hypercholesterolemia (1). AAAs are often asymptomatic and remain undiagnosed until the time of rupture leading to surgical emergency with a high mortality rate of $50-80 \%$ (2). Numerous clinical studies have demonstrated that the risk of AAA rupture markedly increased and surgical repair is required when the maximum diameter reaches $50-55 \mathrm{~mm}(3,4)$. So far, only surgical therapies are available for AAAs but increasing number of reports have suggested that this " $50 \mathrm{~mm}$ diameter criterion" does not fully reflect the severity of AAA in patients completely, limiting the effectiveness of the surgical therapy for majority of AAAs which measure $<50 \mathrm{~mm}$. 
Traditionally, AAA was considered as a simple biomechanical problem due to an irreversible structural change on the aortic wall. However, it has been now been widely accepted that the changes in the biomechanical environment can trigger multiple pathological processes involving morphological, cellular and biochemical changes in the vasculatures of aorta $(5,6)$. Although the exact mechanisms are not clear, the major pathophysiological mechanisms of AAA involve inflammation, oxidative stress, proteolysis and apoptosis (7-10). These are characterized by degradation of elastin fibres, increased collagen expression, excessive immune cells infiltration, vascular smooth muscle cell (VSMC) apoptosis and excessive medial neovascularisation in the AAA segments $(8,11,12)$. A large number of studies have been conducted to assess the efficacy of potential drug therapies including angiotensin converting enzyme (ACE) inhibitor, calcium channel blocker, lipid lowering agents, anti-coagulants and anti-inflammatory agents for reducing AAA expansion rate. Although the initial studies in animal models demonstrated promising effects of these agents in suppressing AAA development and progression in animal models, the randomised clinical trials in human subjects with AAA failed to replicate these findings. To date, no viable drug treatment is available to diminish AAA expansion; current management of AAA largely relies on reduction of cardiovascular factors. Therefore, alternative and novel therapeutic interventions that can slow down AAA progression should be investigated.

Recent proteomic, signalling and metabolomics data have clearly demonstrated the complex interactions between a network of signalling molecules and cells in AAA. Thus, the current "one drug one target" strategy may not be ideally suited to address the different facets of this complex disease effectively. Indeed, some contemporary treatment strategies which focus on the use of multiple compounds/component drugs (e.g., Polypill) $(13,14)$ to overcome the limitations of single target therapy have gained popularity for the management of these complex diseases.

Traditional Chinese medicine (TCM), including Chinese herbal medicines (CHM) and acupuncture, with its unique theory and long history, has been used for the management of cardiovascular diseases for thousands of years in China. In recent years, there has been an increasing recognition of the health benefits of CHM, which are supported mounting evidence from pre-clinical and clinical studies (15-17). Traditionally, $\mathrm{CHM}$ is prescribed in the form of mixtures of plant, animals or minerals and often contains numerous bioactive components. Accumulated evidence has suggested that the multi-component and multi-target property of CHM may help address diseases that have multifactorial/multisystem pathophysiological components (e.g., AAA) (18-20).

In the current paper, we aim to provide an overview of major pathologies of AAA and to review current scientific evidence of the use of CHM highlighting its potential as a novel treatment strategy for AAA. We conducted a literature review on MEDLINE, SCOPUS, Web of Science and Cochrane Library database. The following key words were used either as single or combined searches: "abdominal aortic aneurysm", "traditional Chinese medicine", "herbs", "natural product" and "herbal formulation".

\section{CURRENT TREATMENT OPTIONS AND LIMITATIONS}

Surgical/mechanical intervention is the only effective treatment to prevent AAA rupture and aneurysm-relate death for large AAA $\geq 55 \mathrm{~mm}$ (21). Despite the relatively low failure rate $(\sim 0.3 \%)$ and long term durability of the graft in most patients that survived from the elective open surgical repair $(22,23)$, this complex intervention has a 30 day mortality rate of $5 \%$ and the operative mortality increases markedly in medically unfit patients $(24,25)$. Over the last two decades, minimally invasive endovascular aneurysm repair (EVAR) has gained acceptance as an alternative to open surgical repair (25). Although EVAR has been shown to have clear benefit over conventional open surgical repair, it is associated with a number of issues such as endoleak and graft migration (26). Even though advancement in surgical technique and EVAR have greatly improved the treatment outcomes in patients with large AAA, a large US screening study showed that $90 \%$ of AAAs identified were small AAA ( $<55 \mathrm{~mm})$ (27) where the benefit in reducing AAA rupture is largely outweighed by the risk of surgical intervention (28). Many countries, such as the United Kingdom, provide all men over the age of 65 a one-off non-invasive AAA screening with the aim to reduce AAA-related mortality through early detection of this fatal condition. Majority of patients identified with AAA do not require immediate surgical intervention (29) which dramatically increased the pool of small AAA patients seeking pharmacological treatments to slow down the AAA growth.

Over the last two decades, based on a better understanding of the pathogenesis of AAA, a large number of pre-clinical studies have highlighted a number of potential pharmacological therapies for limiting AAA growth in small animal models and ex vivo experiments of human AAA biopsy (30-35). However, translating of these findings into effective treatments has proven challenging with the reports from major clinical trials (36-38) that have all shown negative results. There are a number of possible reasons accounting for this failure. Firstly, although the current AAA animal models mimic many features of AAA, they do not accurately mirror the chronic pathological changes in human AAA. For instant, AAAs in human usually develop and progress over decades with the presence of an intraluminal thrombus (ILT), while aortic dilatation in animal models occurs within days or weeks without consistent presence of ILT (39). Secondly, most of the current studies using AAA models assessed the effects of interventions on the initiation of AAA rather than its progression. Doxycycline, a tetracycline analogue, has been demonstrated to prevent AAA formation via MMPs inhibition in a variety of animal studies (20-23). However, in a randomized, placebo-controlled, double-blind trial, 18 month treatment with, doxycycline failed to inhibit AAA progression and the need for AAA repair (38). These findings suggest that AAA initiation and formation is a different process from AAA progression, hence, more carefully designed animal studies, such as chronic and pre-established models, are needed to assess the effectiveness of an intervention in suppressing AAA growth rather than initiation. Thirdly, most of the human AAA samples were obtained from the surgical repair of advanced/ large AAA. Studies using these samples only represent the advance 
stage of the disease where pharmacological therapies, which target the earlier stage of the diseases, are unlikely to be effective. Finally, it is worth pointing out that most current treatment strategies only target one specific mechanism (e.g., or. mast cell inhibition) of AAA. Given the fact that AAA involves a complex interplay between numerous cellular and molecular mechanisms, a multicomponent and multi-target approach may be more appropriate in the treatment of AAA.

\section{CHM AS POTENTIAL DRUG THERAPY FOR AAA}

In CHM, multiple herbs are often combined as a complex mixture/ formula for the treatment of various health conditions based on the principle of "Jun (emperor) - Chen (minister) - Zuo (assistant) - Shi (courier)." In complex formulations, individual components can act directly and/or synergistically on individual/multiple therapeutic targets. Some of these interactions may also lead to increased bioavailability or decreased toxicity $(15,40)$. This multicomponent and multi-target approach may offer a better option for the management of diseases with complex pathophysiology, such as AAA $(15,17)$.

\section{Use of CHMs for AAA}

Vascular protective effects of single herbal extracts and/or their isolated bioactive component on AAA have been demonstrated in a number of animal studies (Table 1). However, direct evidence to support the use of complex herbal formulations for AAA is limited even though a number of complex Chinese herbal formulations, such as Si Miao Yong An (SMYA) (51), Sai Lou Tong (SLT) (16), Tong Xin Luo (TXL) capsule (52) and Huang Lian Jie Du Tang (53), have been shown to have vascular protective effects. In a headto-head comparison study between TXL capsule (consisting of Radix ginseng, Buthus martensii, Hirudo medicinalis, Eupolyphaga seu steleophaga, Scolopendra subspinipes, Periostracum cicadae, Paeoniae rubra, Semen ziziphi spinosae, Lignum dalbergiae odoriferae, Lignum santali albi, and Borneolum syntheticum) and simvastatin, both TXL and simvastatin at high dose showed to enhance plaque stability with similar lipid-lowering, antiinflammatory and anti-oxidative effects in a rabbit model of atherosclerosis. Interestingly, low-dose TXL was shown to exhibit similar anti-inflammatory effect to that of high-dose simvastatin, indicating that TXL possesses a greater anti-inflammatory potency compared to simvastatin (54). In a diet-induced atherosclerosis model in rabbits, SMYA [consisting of Flos lonicerae japonicae (Jinyinhua), Radix scrophulariae ningpoensis (Xuanshen), Radix angelicae sinensis (Danggui) and Radix glycyrrhizae uralensis (Gancao)], has been shown to reduce various pathologies of AAA. Oral administration of SMYA significantly lowered abdominal aortic MMP-9 and NF- $\kappa$ B expression and inflammatory cytokines, such as MCP-1, IL-1 and IL-5 systemically. In addition, SMYA promoted atherosclerotic plaque stability through reduction of macrophages infiltration and inhibition ECM degradation (51). Although the underlying effects and molecular mechanisms were not investigated using an AAA specific animal model, findings
TABLE 1 | Summary of the effects of Chinese herbs and herbal bioactive ingredients on AAA in animal models.

\begin{tabular}{|c|c|c|c|}
\hline $\begin{array}{l}\text { Herb Extract/Bio- } \\
\text { active ingredient }\end{array}$ & Model of Study & Proposed Mechanisms & Ref \\
\hline Ginsenosides Rb1 & $\begin{array}{l}\text { ApoE }^{-/-} \text {mouse Angll- } \\
\text { induced AAA }\end{array}$ & $\begin{array}{l}\downarrow \text { MMP production } \\
\text { \inflammatory cell infiltration } \\
\downarrow \text { ECM degradation } \\
\downarrow \text { JNK and p38 MAPK } \\
\text { activation }\end{array}$ & $(41)$ \\
\hline $\begin{array}{l}\text { Monascus } \\
\text { purpureus } \\
\text { (Chinese Red Yeast } \\
\text { Rice) }\end{array}$ & $\begin{array}{l}\text { ApoE }{ }^{-/-} \text {mouse Angll- } \\
\text { induced AAA }\end{array}$ & $\begin{array}{l}\downarrow \text { Serum cholesterol } \\
\downarrow \text { ICAM1 } \downarrow \text { VCAM1 } \\
\downarrow \text { MMP-2 and -9 expression } \\
\uparrow \text { Macrophage migration } \\
\text { inhibitory factor }\end{array}$ & $(42)$ \\
\hline Quercetin & $\begin{array}{l}\text { C57/BL6 mouse } \\
\text { extraluminal calcium } \\
\text { chloride-induced AAA }\end{array}$ & $\begin{array}{l}\downarrow \text { superoxide dismutase } \\
\text { activities } \downarrow \text { glutathione } \\
\text { peroxidase expression } \\
\downarrow \text { JNK signalling } \\
\downarrow \text { MMP-2 and -9 activity }\end{array}$ & $(43)$ \\
\hline $\begin{array}{l}\text { Epigallocatechin-3- } \\
\text { gallate (Green tea } \\
\text { polyphenol) }\end{array}$ & $\begin{array}{l}\text { Rat extraluminal } \\
\text { calcium chloride- } \\
\text { induced AAA }\end{array}$ & $\begin{array}{l}\downarrow \text { Inflammatory cytokine } \\
\text { expression } \\
\downarrow \text { MMP-9 expression and } \\
\text { activity } \\
\uparrow T \text { Tissue inhibitors of MMP- } 1\end{array}$ & (44) \\
\hline Resveratrol & $\begin{array}{l}\text { ApoE }{ }^{-/-} \text {Ace } 2^{-/ y} \text { mouse } \\
\text { Angll-induced AAA }\end{array}$ & $\begin{array}{l}\uparrow \text { serum and aortic ACE2 } \\
\text { activity } \\
\downarrow \text { Sirtuin } 1 \text { activity } \\
\downarrow \text { MMP-2 and }-9 \text { expression } \\
\downarrow \text { Angiotensin type- } 1 \\
\text { receptor } \\
\downarrow \text { Akt and ERK signalling }\end{array}$ & (33) \\
\hline Salvianolic acid C & $\begin{array}{l}\text { ApoE }^{-/-} \text {mouse Angll- } \\
\text { induced AAA }\end{array}$ & $\begin{array}{l}\downarrow \text { MMP-2 and -9 activity } \\
\downarrow \text { Elastin fragmentation } \\
\downarrow \text { Macrophage infiltration }\end{array}$ & $(45)$ \\
\hline Salvianolic acid A & $\begin{array}{l}\text { ApoE }^{-/-} \text {mouse Angll- } \\
\text { induced AAA }\end{array}$ & $\begin{array}{l}\downarrow \text { MMP-2 and }-9 \text { activity } \\
\downarrow \text { Elastin fragmentation } \\
\downarrow \text { Macrophage infiltration }\end{array}$ & $(46)$ \\
\hline Baicalein & $\begin{array}{l}\text { ApoE }^{-/-} \text {mouse Angll- } \\
\text { induced AAA }\end{array}$ & $\begin{array}{l}\downarrow \text { MMP-2 and }-9 \text { activity } \\
\downarrow \text { Angiotensin type } 1 \text { receptor } \\
\downarrow \text { MAPK signalling } \\
\downarrow \text { Inflammatory cell infiltration } \\
\downarrow \text { Reactive oxygen species } \\
\text { (ROS) production }\end{array}$ & $(47)$ \\
\hline $\begin{array}{l}\text { Ginkgo biloba } \\
\text { extract (EGb 761) }\end{array}$ & $\begin{array}{l}\text { C57/BL6 mouse } \\
\text { extraluminal calcium } \\
\text { chloride-induced AAA }\end{array}$ & $\begin{array}{l}\downarrow \text { Elastin fragmentation } \\
\downarrow \text { MMP-2 and -9 activity } \\
\downarrow R O S \text { production } \\
\downarrow N F \kappa B \text { signalling }\end{array}$ & (48) \\
\hline $\begin{array}{l}\text { Dietary } \\
\text { phytoestrogens }\end{array}$ & $\begin{array}{l}\text { C57/BL6 mouse } \\
\text { intraluminal elastase- } \\
\text { induced AAA }\end{array}$ & $\begin{array}{l}\downarrow \text { Inflammatory cell infiltration } \\
\downarrow \text { MMP-9 activity } \\
\text { \Inflammatory cytokines } \\
\text { level }\end{array}$ & (49) \\
\hline Curcumin & $\begin{array}{l}\text { ApoE }^{-/-} \text {mouse Angll- } \\
\text { induced AAA }\end{array}$ & $\begin{array}{l}\text { } S O D \text { expression } \\
\downarrow \text { ERK } 1 / 2 \text { signalling } \\
\text { \Inflammatory cytokines } \\
\text { level } \\
\downarrow \text { Macrophage infiltration }\end{array}$ & (50) \\
\hline
\end{tabular}

MMP, Matrix metalloproteinases; JNK, c-Jun N-terminal kinases; ICAM1, Intercellular Adhesion Molecule 1; VCAM1, Vascular Adhesion Molecule 1; ERK, Extracellular signal-regulated kinases; NFKB, Nuclear Factor Kappa-Light-Chain-Enhancer of Activated B Cell; SOD, Superoxide Dismutase.

from this study has clearly demonstrated the potential beneficial effects of SMYA for AAA.

A recent study by Xiong et al (55) in $\mathrm{ApoE}^{-/-}$mouse showed that Shexiang Tongxin dropping pill (STDP), a seven herbs 
formulation consisting Radix rhizoma ginseng, Calculus bovis, bear gall, Venenum bufonis, borneol, moschus, and Salvia miltiorrhiza, produced its anti-atherosclerotic effects via multiple mechanisms including reduced pro-inflammation cytokines (IL-2, Ilt-6, TNF- $\alpha$ and $\gamma$-IFN), upregulated serum anti-oxidative enzyme levels (superoxide dismutase (SOD) and glutathione), decreased aortic expression of miR-21a, miR-126a, miR-155, and increased miR20a expression (55). It is worth noting that differential expression of various miRNAs has been demonstrated in aneurysmal aortic samples which is strongly associated with the development of AAA. For example, miR155 has been shown to play a vital role in vascular inflammation via programming of macrophages (56). In line with that, a later study has demonstrated that miR 155 is overexpressed in both the aneurysmal site and serum of AAA patient (57). Moreover, both miR-21a and miR-126, which act as key regulators of vascular remodelling by controlling VSMC apoptosis and vascular inflammation, have been shown to be upregulated in abdominal aortic aneurysmal tissues and $(58,59)$. In another study, Xiaoxianggou, consisting of Ficus pandurata hance var. angustifolia Cheng, Ficus panduram Hane var. hoiophylla Migo and Ficus erecta Thunb.var. bcecheyana (Hook.et Am.) King., has been shown to reduce atherosclerotic lesion formation via downregulation of miR-203 expression in an endogenous high Ang II $\mathrm{ApoE}^{-/-}$mouse model (60). miR-203 has been shown to promote VSMC dysfunction and aortic stiffness in aged mouse (61). Therefore, modulation of miRNA expressions by CHMs could represent a novel AAA management strategy.

Western medicine is characterized by its rapid effect in controlling and relieving of symptoms, unfortunately the adverse effects associated with some of the Western or synthetic medicines have limited their applications (62-65). It has been reported that CHMs when used in conjunction with Western medicine can produce greater therapeutic effects and/or less adverse effects than Western medicine alone $(66,67)$. Didang decoction (DDD), a traditional Chinese formula (consisting of Rheum rhabarbarum, Hirudo medicinalis, Prunus persica and Tabanus atratus), has been shown to produce a greater effect on attenuating vascular lesion and endothelial injury than metformin in a diabetic model in rats (68). Jiang et al showed that artesunate, a derivate of artemisinin from sweet wormwood, attenuated formation of atherosclerosis lesion via reduction of vascular inflammation in high-fat fed $\mathrm{ApoE}^{-/-}$mice. When combined with rosuvastatin, a lipid-lowering agent, artesunate produced a greater attenuation of atherosclerosis compared to artesunate and rosuvastain alone (69).

A recent systematic review and meta-analysis has reported that a combined therapy of CHMs and warfarin is more effective in preventing total thromboembolic events in patients with atrial fibrillation (70). Zhibitai, is a Chinese herbal comprised of a family of naturally occurring statins to treat blood lipid disease. When combined with low dose of atorvastatin $(10 \mathrm{mg})$, Zhibitai has been shown to improve blood lipid profile and reduce inflammation, similar to that of higher doses of atorvastatin $(20$ and $40 \mathrm{mg}$ ) with less adverse effects in patients with coronary heart disease (67). Given the role of hyperlipidemia and inflammation in AAA development and growth, the results of this study suggest that the combination therapy between CHM and Western medicine may offer additional benefits.

\section{Mechanisms of Action}

It is now generally accepted that inflammation, oxidative stress and extracellular matrix (ECM) degradation are the three fundamental factors contributing to the development of AAA $(8,71-73)$. In this section, the mechanisms of action underlying the effects of $\mathrm{CHM}$ against these major pathophysiological processes of AAA are discussed.

\section{Anti-Inflammation}

Chronic inflammation plays a significant role in the development and progression of AAA. Although little is known about the initiation of AAA development, histological analysis has revealed a transmural degenerative process in the aortic wall involving a number of inflammatory cells, such as macrophages, monocytes and lymphocytes $(31,35,74)$. In addition to dense inflammatory cells infiltration within the outer media and adventitia of the aortic wall, multiple pro-inflammatory cytokines and mediators have also been identified in the aortic aneurysm as well as in the circulation $(32,72,75)$. The enhanced pro-inflammatory cytokines levels promote activation of immune cells and stimulate production of matrix metalloproteinase (MMP) at the aneurysmal site, directly contributing to the degradation of major extracellular structural proteins such as elastin and collagen. Although whether inflammation and MMP activation is the direct cause of AAA remains to be determined, the critical role of inflammation and immunity changes in AAA is well accepted. Indeed, a large body of evidence have demonstrated that anti-inflammatory or immune-based intervention may be an effective therapeutic and preventive approach for AAA. For example, doxycycline, a tetracycline analogue, has been demonstrated to prevent AAA formation via MMPs inhibition in a variety of animal studies (76-79) and to limit AAA growth in two small clinical trials $(7,80)$. Similarly, hydroxymethylglutaryl-coenzyme A (HMG CoA) reductase inhibitors (statin) has also been suggested to benefit AAA through its ability to inhibit several MMPs and immune cells activity and downregulation of various inflammation signalling molecules expression as demonstrated in a number of in vitro and in vivo studies (81-84). Although doxycycline and statins failed to limit AAA growth in clinical trials $(21,85,86)$, the importance of anti-inflammation strategies in AAA management should not be ignored. Instead, more specific MMP inhibitors with better pharmacokinetics and tissue absorption should be developed.

A large number of $\mathrm{CHMs}$ possess anti-inflammatory properties, some of which have demonstrated beneficial effects in the treatment and prevention of various cardiovascular conditions. For example, Aralia cordata (Tu Dan Gui), have been shown to have significant anti-inflammatory effects. Ent-pimara-8(14), 15-dien,19-oic acid (pimaradienoic acid, PA) is believed to be responsible for this effect through reduction of the nitric oxide (NO), prostaglandin E2 (PGE2) and interleukin-6 (IL-6) generation and inducible NO synthase (iNOS) and cyclooxygenase-2 (COX-2) expression via inactivation of MAPK signalling following I $\mathrm{KB}$ degradation and NF- $\kappa B$ activation in cultured macrophages (87). Similarly, kaurenoic acid (KA), a major diterpenoid from the root of Aralia continentalis (Dong Bei Tu Dan Gui), displayed anti-inflammatory effects in both in vitro and in vivo models via inhibition of iNOS 
and COX-2 expression (88). A later study by the same group showed that the anti-inflammatory effects of KA is mediated via activation of the nuclear factor erythroid 2-related factor 2 (Nrf2) (89). Considering the demonstrated role of COX-2, iNOS, NF- $\kappa B$ and Nrf2 signalling in the progression and development of AAA (90-92), these studies have highlighted the potential of CHMs in control of various inflammatory processes during AAA and its related vascular conditions, such as atherosclerosis.

\section{Anti-Oxidative Stress}

Reactive oxygen species (ROS) are a small group of chemically reactive molecules which are involved in vascular functions such as smooth muscle contraction, angiogenesis and endothelial functions (93). However, excessive ROS generation due to dysfunction of either enzymic and non-enzymic mechanisms [such as enhanced activation of xanthine oxidase (XO), lipoxygenase (LOX) and NADPH oxidase (NOX), overexpression of iNOS and impaired mitochondrial respiratory electron transport chain (ETC)] is closely associated with a number of vascular diseases, including AAA $(94,95)$. Indeed, increased oxidative stress and ROS over generation has been shown to play a pivotal role in AAA progression and development $(71,96)$. For instant, both in vitro and in vivo studies have demonstrated that overproduction of ROS exacerbates various AAA pathogenesis including vascular smooth muscle cell (VSMC) migration, metalloproteinases (MMP) activation, extracellular matrix (ECM) degradation and endothelium dysfunction (92, 97-100). In human studies, high-grade oxidative stress has been observed in AAA patients, suggesting the possible protective effect of anti-oxidant supplement for AAA $(101,102)$. Xiong et al showed that inhibition of NADPH oxidase by apocynin significantly suppressed AAA formation in a mouse model of AAA (103). Later study showed that angiotensin II-induced AAA is exacerbated in NADPH oxidase deficiency mice (104). These studies have clearly demonstrated that ROS is an important target to reduce AAA progression $(103,105,106)$.

Many CHMs have been shown to have remarkable antioxidative properties $(107,108)$. For instance, Sailuotong (SLT), a standardised three-herb formula combining specific dosages of Panax ginseng (Ren Shen), Ginkgo biloba (Yin Xin Ye), and Crocus sativus (Zhuang Hong Hua), has been shown to protect endothelial cell from ROS-induced apoptosis via enhancement of superoxide dismutase (SOD) activity and suppression of caspase-3 activation (16). EGb 761, a standardized extract of Ginkgo biloba is a well-known anti-oxidant $(109,110)$. Interestingly, several studies have shown that extract of Ginkgo biloba significantly reduced MMP production. In line with this, Wang et al (48) showed that EGb 761 limited AAA development in a mouse model possibly through reduction of oxidative stress and aortic MMP-2 and -9 activities (48). Resveratrol, a plantderived polyphenolic compound, has been shown to prevent the formation of AAA induced by calcium chloride in mouse via multiple mechanisms, including anti-oxdiation and antiinflammation (111). In a recent study, baicalein (BAI), the major bioactive component of Radix Scutellariae Baicalensis (Huang Qin), decreased the incidence of AAA in angiotensin II (AngII)induced $\mathrm{AAA}$ in $\mathrm{ApoE}^{-/-}$mouse. Moreover, BAI treatment significantly reduced AngII-induced aortic ROS production and MMP-2 and -9 activation (47). It is important to point out that, while these preclinical studies have clearly demonstrated anti-oxidative properties of CHMs, their clinical effects in AAA are yet to be determined.

\section{Anti-ECM Degradation}

The development of AAA is considered as a multi-stage process consisting of the initial loss of elastin mediated by VSMCs and collagen deposition followed by the production of ECM fragments and matrix destruction as a consequence of inflammation and eventually rupture $(112,113)$. It is generally accepted that cathepsins and matrix metalloproteinases (MMPs) are the two major proteases responsible for the ECM degradation $(114,115)$. High level of MMPs, including MMP-8, -9, -12 and 19, have been detected in advanced surgically removed aneurysm (116-119). In animal studies, knockout of MMP-2 and -9 reduced aneurysm formation $(120,121)$. Moran et al (122) have demonstrated that osteoprotegerin (OPG) is positively associated with AAA in human (122) and knockout of OPG limited AAA progression and reduced aortic MMP-2 and -9 expression in AngII-infused $\mathrm{ApoE}^{-/-}$mouse (34). Similarly, deficiency of cathepsin K or cathepsin $\mathrm{G}$ attenuated AAA formation in multiple rodent models of AAA $(123,124)$. A large number of studies have been conducted to identify potential pharmaceutical candidates (e.g., MMP inhibitor) to inhibit ECM degradation. Unfortunately, most of these studies failed to lead to viable interventions despite promising results were obtained from animal studies or small scale clinical trials.

Several studies have demonstrated inhibitory effects of natural products on MMP. Abraham et al (2005) showed that Triphala, a traditional herbal concoction consisting of Emblica officinalis, Terminalia bellirica and Terminalia chebula, has strong inhibitory activity on MMPs using gelatin zymography (125). In a similar study, Azadirachta indica (Neem) and Aloe vera have been shown to inhibit MMP-2 and -9 activity (126). In human aortic VSMC, carnosic acid, a phenolic compound found in various herbs such as Rosmarinus officinalis and Salvia officinalis, has been shown to inhibit MMP-9 expression through down-regulation of NF- $\kappa B$ (127). Studies have shown that activation of $c$-jun $\mathrm{N}$-terminal kinase is a major mechanism of MMPs activation (128). Pimaric acid, a purified compound from Aralia cordata, has been shown to inhibit MMP-9 production via inhibition of $c$-jun activation in human aortic VSMC (129). In animal study, quercetin, a natural flavonoid found in many Chinese herbs, have been shown to limit AAA development and reduce aortic expression of MMP-2, -9, cathepsin B and cathepsin $\mathrm{K}$ in the calcium chloride-induced AAA model. Additionally, quercetin also increased tissue inhibitors of metalloproteinases (TIMP)-1 gene expression (130). A later study from the same group showed that the quercetin-mediated protective effects is regulated via the JNK/AP-1 signalling pathway (43). These studies clearly demonstrated the potential benefits of herbal medicine in the treatment of AAA and atherosclerosis via modulation of MMPs activity and their associated signalling pathways. 


\section{CONCLUSION}

AAA is a multifactorial disease caused by oxidative stress and vascular inflammation ultimately leading to the destruction of the ECM structural proteins. Despite substantial efforts invested in the development of pharmaceutical interventions for AAA, little success has been achieved. Recent evidence clearly demonstrated the beneficial effects of CHMs against various major pathologies of AAA. Large number of single herb extract and their isolated active components have been studied in detail using various well-established animal model of AAA, including AngII-induced and calcium chloride-induced AAA mouse models. In contrast, the support of the potential of complex herbal formulations of AAA is largely based on animal model of atherosclerosis. It is important to point out that although atherosclerosis and AAA share many predisposing risk factors and exhibit similar immune and inflammatory cell infiltration at the lesion site, the underlying mechanisms mediating the development and progression are not always the same between these two diseases. Similarly, although rodent model of AAA been used extensively to understand the pathophysiology and evaluate potential treatment for AAA, these models of AAA do not fully recapitulate the condition in human. Therefore, the result observed from these animal studies should be interpreted with caution.

Similar to many Western therapies that have shown promising pre-clinical data, early evidence exists from pre-clinical studies demonstrating that CHMs (either as single herbs or as complex herbal formulations) also possess beneficial effects against AAA and/or other vascular pathologies via multiple mechanisms.

\section{REFERENCES}

1. Pande RL, Beckman JA. Abdominal aortic aneurysm: populations at risk and how to screen. J Vasc Interv Radiol (2008) 19(6 Suppl):S2-8. doi: 10.1016/j. jvir.2008.03.010

2. Kuivaniemi H, Ryer EJ, Elmore JR, Hinterseher I, Smelser DT, Tromp G. Update on abdominal aortic aneurysm research: from clinical to genetic studies. Scientifica (2014) 2014(11):1-14. doi: 10.1155/2014/564734

3. Brown PM, Sobolev B, Zelt DT. Selective management of abdominal aortic aneurysms smaller than $5.0 \mathrm{~cm}$ in a prospective sizing program with gender-specific analysis. J Vasc Surg (2003) 38(4):762-5. doi: 10.1016/S07415214(03)00551-2

4. Hall AJ, Busse EF, Mccarville DJ, Burgess JJ. Aortic wall tension as a predictive factor for abdominal aortic aneurysm rupture: improving the selection of patients for abdominal aortic aneurysm repair. Ann Vasc Surg (2000) 14(2):152-7. doi: 10.1007/s100169910027

5. Cicco G, Cicco S. The influence of oxygen supply, hemorheology and microcirculation in the heart and vascular systems. Adv Exp Med Biol (2010) 662:33-9. doi: 10.1007/978-1-4419-1241-1_4

6. Yamane T, Mitsumata M, Yamaguchi N, Nakazawa T, Mochizuki K, Kondo $\mathrm{T}$, et al. Laminar high shear stress up-regulates type IV collagen synthesis and down-regulates MMP-2 secretion in endothelium. A quantitative analysis. Cell Tissue Res (2010) 340(3):471-9. doi: 10.1007/s00441-0100968-6

7. Baxter BT, Pearce WH, Waltke EA, Littooy FN, Hallett JW, Kent KC, et al. Prolonged administration of doxycycline in patients with small asymptomatic abdominal aortic aneurysms: report of a prospective (Phase II) multicenter study. J Vasc Surg (2002) 36(1):1-12. doi: 10.1067/mva.2002.125018
These results highlight the advantage of multi-component and multi-target properties of CHM in the treatment for AAA. Robust randomized, controlled trials are needed to confirm and validate the clinical effectiveness of CHMs. It is important to point out that the translational potential of CHM approaches for AAA remains unknown and it is possible that $\mathrm{CHMs}$ would also fail to treat AAA in large, controlled trial given the complex nature of $\mathrm{AAA}$ and the stages at which patients can be identified. Moreover, combining Western medicine and CHM treatment may be a novel strategy to slow down AAA growth, this potentially important intervention should be fully explored with more well-designed clinical study. It will be especially important to test if combined treatment approach could be a valid option to control major AAA pathologies and AAA growth in patients who do not response to conventional therapy satisfactorily. Additionally, more research is needed to understand the interactions and synergistic effects among the multiple bioactive components of CHMs.

\section{AUTHOR CONTRIBUTIONS}

SS and DC conceived the study. AB, DC, HK and SS designed the study. SS searched all the relative papers and drafting this manuscript. DC, HK, NW and AB revised the manuscript. All authors read and approved the final manuscript.

\section{FUNDING}

SS is supported in part by a Cardiac Health Institute Fellowship.
8. Macsweeney ST, Powell JT, Greenhalgh RM. Pathogenesis of abdominal aortic aneurysm. Br J Surg (1994) 81(7):935-41. doi: 10.1002/bjs.1800810704

9. Shah PK. Inflammation, metalloproteinases, and increased proteolysis: an emerging pathophysiological paradigm in aortic aneurysm. Circulation (1997) 96(7):2115-7. doi: 10.1161/01.CIR.96.7.2115

10. Chen HZ, Wang F, Gao P, Pei JF, Liu Y, Xu TT, et al. Age-associated sirtuin 1 reduction in vascular smooth muscle links vascular senescence and inflammation to abdominal aortic aneurysm. Circ Res (2016) 119(10):107688. doi: 10.1161/CIRCRESAHA.116.308895

11. Carmo M, Colombo L, Bruno A, Corsi FR, Roncoroni L, Cuttin MS, et al. Alteration of elastin, collagen and their cross-links in abdominal aortic aneurysms. Eur J Vasc Endovasc Surg (2002) 23(6):543-9. doi: 10.1053/ ejvs.2002.1620

12. Schubl S, Tsai S, Ryer EJ, Wang C, Hu J, Kent KC, et al. Upregulation of protein kinase cdelta in vascular smooth muscle cells promotes inflammation in abdominal aortic aneurysm. J Surg Res (2009) 153(2):181-7. doi: 10.1016/j. jss.2008.04.032

13. Carey KM, Comee MR, Donovan JL, Kanaan AO. A polypill for all? Critical review of the polypill literature for primary prevention of cardiovascular disease and stroke. Ann Pharmacother (2012) 46(5):688-95. doi: 10.1345/ aph.1Q621

14. Jaques H. The polypill concept: the future. Eur Heart J (2011) 32(22):2732-3.

15. Chang D, Liu J, Bilinski K, Xu L, Steiner GZ, Seto SW, et al. Herbal medicine for the treatment of vascular dementia: an overview of scientific evidence. Evid Based Complement Alternat Med (2016) 2016(3):1-15. doi: $10.1155 / 2016 / 7293626$

16. Seto S, Chang D, Ko W, Zhou X, Kiat H, Bensoussan A, et al. Sailuotong Prevents Hydrogen Peroxide (H2O2)-Induced Injury in EA.hy926 Cells. Int $J$ Mol Sci (2017) 18(1):95. doi: 10.3390/ijms18010095 
17. Seto SW, Yang GY, Kiat H, Bensoussan A, Kwan YW, Chang D. Diabetes mellitus, cognitive impairment, and traditional Chinese medicine. Int $J$ Endocrinol (2015) 2015(1):1-14. doi: 10.1155/2015/810439

18. Bajda M, Guzior N, Ignasik M, Malawska B. Multi-target-directed ligands in Alzheimer's disease treatment. Curr Med Chem (2011) 18(32):4949-75. doi: 10.2174/092986711797535245

19. Chen YY, Li Q, Pan CS, Yan L, Fan JY, He K, et al. QiShenYiQi Pills, a compound in Chinese medicine, protects against pressure overload-induced cardiac hypertrophy through a multi-component and multi-target mode. Sci Rep (2015) 5(1):11802. doi: 10.1038/srep11802

20. Zhang X, He X, Chen Q, Lu J, Rapposelli S, Pi R. A review on the hybrids of hydroxycinnamic acid as multi-target-directed ligands against Alzheimer's disease. Bioorg Med Chem (2018) 26(3):543-50. doi: 10.1016/j. bmc.2017.12.042

21. Golledge J, Norman PE, Murphy MP, Dalman RL. Challenges and opportunities in limiting abdominal aortic aneurysm growth. J Vasc Surg (2017) 65(1):225-33. doi: 10.1016/j.jvs.2016.08.003

22. Hallett JW, Marshall DM, Petterson TM, Gray DT, Bower TC, Cherry KJ, et al. Graft-related complications after abdominal aortic aneurysm repair: reassurance from a 36-year population-based experience. J Vasc Surg (1997) 25(2):277-86. doi: 10.1016/S0741-5214(97)70349-5

23. Johnston KW. Influence of sex on the results of abdominal aortic aneurysm repair. Canadian society for vascular surgery aneurysm study group. J Vasc Surg (1994) 20(6):914-23.

24. Johnston KW. Multicenter prospective study of nonruptured abdominal aortic aneurysm. Part II. Variables predicting morbidity and mortality. J Vasc Surg (1989) 9(3):437-47. doi: 10.1016/S0741-5214(89)70007-0

25. Norwood MG, Lloyd GM, Bown MJ, Fishwick G, London NJ, Sayers RD. Endovascular abdominal aortic aneurysm repair. Postgrad Med J (2007) 83(975):21-7. doi: 10.1136/pgmj.2006.051177

26. de La Motte L, Falkenberg M, Koelemay MJ, Lönn L. Is EVAR a durable solution: indications for re-interventions. J Cardiovasc Surg (2018). doi: 10.23736/S0021-9509.18.10388-0

27. Lederle FA, Johnson GR, Wilson SE, Chute EP, Littooy FN, Bandyk D, et al. Prevalence and associations of abdominal aortic aneurysm detected through screening. Aneurysm Detection and Management (ADAM) Veterans Affairs Cooperative Study Group. Ann Intern Med (1997) 126(6):441-9.

28. Fleming C, Whitlock EP, Beil TL, Lederle FA. Screening for abdominal aortic aneurysm: a best-evidence systematic review for the U.S. Preventive Services Task Force. Ann Intern Med (2005) 142(3):203-11. doi: 10.7326/0003-4819142-3-200502010-00012

29. Bath MF, Sidloff D, Saratzis A,Bown MJ, UK Aneurysm Growth Study investigators. Impact of abdominal aortic aneurysm screening on quality of life. Br J Surg (2018) 105(3):203-8. doi: 10.1002/bjs.10721

30. Clancy P, Seto SW, Koblar SA, Golledge J. Role of the angiotensin converting enzyme 1/angiotensin II/angiotensin receptor 1 axis in interstitial collagenase expression in human carotid atheroma. Atherosclerosis (2013) 229(2):331-7. doi: $10.1016 /$ j.atherosclerosis.2013.05.022

31. Krishna SM, Seto SW, Jose R, Li J, Moxon J, Clancy P, et al. High serum thrombospondin-1 concentration is associated with slower abdominal aortic aneurysm growth and deficiency of thrombospondin-1 promotes angiotensin II induced aortic aneurysm in mice. Clin Sci (2017) 131(12):1261-81. doi: $10.1042 /$ CS20160970

32. Krishna SM, Seto SW, Jose RJ, Li J, Morton SK, Biros E, et al. Wnt signaling pathway inhibitor sclerostin inhibits angiotensin II-induced aortic aneurysm and atherosclerosis. Arterioscler Thromb Vasc Biol (2017) 37(3):553-66. doi: 10.1161/ATVBAHA.116.308723

33. Moran CS, Biros E, Krishna SM, Wang Y, Tikellis C, Morton SK, et al. Resveratrol inhibits growth of experimental abdominal aortic aneurysm associated with upregulation of angiotensin-converting enzyme 2 . Arterioscler Thromb Vasc Biol (2017) 37(11):2195-203. doi: 10.1161/ ATVBAHA.117.310129

34. Moran CS, Jose RJ, Biros E, Golledge J. Osteoprotegerin deficiency limits angiotensin II-induced aortic dilatation and rupture in the apolipoprotein E-knockout mouse. Arterioscler Thromb Vasc Biol (2014) 34(12):2609-16. doi: 10.1161/ATVBAHA.114.304587

35. Seto SW, Krishna SM, Moran CS, Liu D, Golledge J. Aliskiren limits abdominal aortic aneurysm, ventricular hypertrophy and atherosclerosis in an apolipoprotein-E-deficient mouse model. Clin Sci (2014) 127(2):123-34. doi: $10.1042 / C S 20130382$

36. Hackmann AE, Rubin BG, Sanchez LA, Geraghty PA, Thompson RW, Curci JA. A randomized, placebo-controlled trial of doxycycline after endoluminal aneurysm repair. J Vasc Surg (2008) 48(3):519-26. doi: 10.1016/j. jvs.2008.03.064

37. Lindeman JH, Abdul-Hussien H, van Bockel JH, Wolterbeek R, Kleemann R. Clinical trial of doxycycline for matrix metalloproteinase-9 inhibition in patients with an abdominal aneurysm: doxycycline selectively depletes aortic wall neutrophils and cytotoxic T cells. Circulation (2009) 119(16):2209-16. doi: 10.1161/CIRCULATIONAHA.108.806505

38. Meijer CA, Stijnen T, Wasser MN, Hamming JF, van Bockel JH,Lindeman $\mathrm{JH}$, et al. Doxycycline for stabilization of abdominal aortic aneurysms: a randomized trial. Ann Intern Med (2013) 159(12):815-23. doi: 10.7326/00034819-159-12-201312170-00007

39. Sénémaud J, Caligiuri G, Etienne H, Delbosc S, Michel JB, Coscas R. Translational relevance and recent advances of animal models of abdominal aortic aneurysm. Arterioscler Thromb Vasc Biol (2017) 37(3):401-10. doi: 10.1161/ATVBAHA.116.308534

40. Wagner H, Ulrich-Merzenich G. Synergy research: approaching a new generation of phytopharmaceuticals. Phytomedicine (2009) 16(2-3):97-110. doi: 10.1016/j.phymed.2008.12.018

41. Zhang XJ, He C, Tian K, Li P, Su H, Wan JB. Ginsenoside Rb1 attenuates angiotensin II-induced abdominal aortic aneurysm through inactivation of the JNK and p38 signaling pathways. Vascul Pharmacol (2015) 73:86-95. doi: 10.1016/j.vph.2015.04.003

42. Xie X, Wang Y, Zhang S, Zhang G, Xu Y, Bi H, et al. Chinese red yeast rice attenuates the development of angiotensin II-induced abdominal aortic aneurysm and atherosclerosis. J Nutr Biochem (2012) 23(6):549-56. doi: 10.1016/j.jnutbio.2011.02.011

48. Wang L, Bai Y, Wang B, Cui H, Wu H, Lv JR, et al. Suppression of experimental abdominal aortic aneurysms in the mice by treatment with Ginkgo biloba extract (EGb 761). J Ethnopharmacol (2013) 150(1):308-15. doi: 10.1016/j. jep.2013.08.048

49. Lu G, Su G, Zhao Y, Johnston WF, Sherman NE, Rissman EF, et al. Dietary phytoestrogens inhibit experimental aneurysm formation in male mice. J Surg Res (2014) 188(1):326-38. doi: 10.1016/j.jss.2013.11.1108

50. Hao Q, Chen X, Wang X, Dong B, Yang C. Curcumin attenuates angiotensin II-induced abdominal aortic aneurysm by inhibition of inflammatory response and ERK signaling pathways. Evid Based Complement Alternat Med (2014) 2014:1-10. doi: 10.1155/2014/270930

43. Wang L, Cheng X, Li H, Qiu F, Yang N, Wang B, et al. Quercetin reduces oxidative stress and inhibits activation of c-Jun N-terminal kinase/activator protein-1 signaling in an experimental mouse model of abdominal aortic aneurysm. Mol Med Rep (2014) 9(2):435-42. doi: $10.3892 / \mathrm{mmr} .2013 .1846$

44. Setozaki S, Minakata K, Masumoto H, Hirao S, Yamazaki K, Kuwahara $\mathrm{K}$, et al. Prevention of abdominal aortic aneurysm progression by oral administration of green tea polyphenol in a rat model. J Vasc Surg (2017) 65(6):1803-12. doi: 10.1016/j.jvs.2016.06.003

45. Wu P, Han N, Yu H, Wang L, Li X, Dong Z, et al. Amelioration of salvianolic acid $\mathrm{C}$ on aortic structure in apolipoprotein E-deficient mice treated with angiotension II. Life Sci (2016) 166:75-81. doi: 10.1016/j.lfs.2016.09.012

46. Zhang T, Xu J, Li D, Chen J, Shen X, Xu F, et al. Salvianolic acid A, a matrix metalloproteinase-9 inhibitor of Salvia miltiorrhiza, attenuates aortic aneurysm formation in apolipoprotein E-deficient mice. Phytomedicine (2014) 21(10):1137-45. doi: 10.1016/j.phymed.2014.05.003

47. Wang F, Chen H, Yan Y, Liu Y, Zhang S, Liu D. Baicalein protects against the development of angiotensin II-induced abdominal aortic aneurysms by blocking JNK and p38 MAPK signaling. Sci China Life Sci (2016) 59(9):940-9. doi: 10.1007/s11427-015-0277-8

51. Peng L, Li M, Xu YZ, Zhang GY, Yang C, Zhou YN, et al. Effect of Si-MiaoYong-An on the stability of atherosclerotic plaque in a diet-induced rabbit model. J Ethnopharmacol (2012) 143(1):241-8. doi: 10.1016/j.jep.2012.06.030

52. Mao C, Fu XH, Yuan JQ, Yang ZY, Chung VC, Qin Y, et al. Tong-xin-luo capsule for patients with coronary heart disease after percutaneous coronary intervention. Cochrane Database Syst Rev (2015) 5(5):CD010237. doi: 10.1002/14651858.CD010237.pub2 
53. Li X, Li C, Ji X, Song Z, Wang L, Zhang J, et al. Huang-Lian-Jie-Du-Tang inhibits myocardial remodeling in a rat model of metabolic syndrome. $J$ Ethnopharmacol (2008) 119(2):259-65. doi: 10.1016/j.jep.2008.07.019

54. Zhang L, Liu Y, Lu XT, Wu YL, Zhang C, Ji XP, et al. Traditional Chinese medication Tongxinluo dose-dependently enhances stability of vulnerable plaques: a comparison with a high-dose simvastatin therapy. Am J Physiol Heart Circ Physiol (2009) 297(6):H2004-2014. doi: 10.1152/ ajpheart.00208.2009

55. Xiong M, Jia C, Cui J, Wang P, du X, Yang Q, et al. Shexiang Tongxin dropping pill attenuates atherosclerotic lesions in ApoE deficient mouse model. $J$ Ethnopharmacol (2015) 159:84-92. doi: 10.1016/j.jep.2014.11.013

56. Nazari-Jahantigh M, Wei Y, Noels H, Akhtar S, Zhou Z, Koenen RR, et al. MicroRNA-155 promotes atherosclerosis by repressing Bcl6 in macrophages. J Clin Invest (2012) 122(11):4190-202. doi: 10.1172/JCI61716

57. Biros E, Moran CS, Wang Y, Walker PJ, Cardinal J, Golledge J. microRNA profiling in patients with abdominal aortic aneurysms: the significance of miR-155. Clin Sci (2014) 126(11):795-803. doi: 10.1042/CS20130599

58. Kin K, Miyagawa S, Fukushima S, Shirakawa Y, Torikai K, Shimamura K, et al. Tissue- and plasma-specific MicroRNA signatures for atherosclerotic abdominal aortic aneurysm. J Am Heart Assoc (2012) 1(5):e000745. doi: 10.1161/JAHA.112.000745

59. Fu XM, Zhou YZ, Cheng Z, Liao XB, Zhou XM, Fu XM. MicroRNAs: novel players in aortic aneurysm. Biomed Res Int (2015) 2015(4):p. 831641-9. doi: $10.1155 / 2015 / 831641$

60. Nie W, Zhang X, Yan H, Li S, Zhu W, Fan F, et al. Xiaoxianggou attenuates atherosclerotic plaque formation in endogenous high Ang II ApoE(-/-) mice via the inhibition of miR-203 on the expression of Ets-2 in endothelial cells. Biomed Pharmacother (2016) 82:173-9. doi: 10.1016/j.biopha.2016.04.065

61. Nicholson CJ, Seta F, Lee S, Morgan KG. MicroRNA-203 mimics age-related aortic smooth muscle dysfunction of cytoskeletal pathways. J Cell Mol Med (2017) 21(1):81-95. doi: 10.1111/jcmm.12940

62. Chao J, Dai Y, Verpoorte R, Lam W, Cheng YC, Pao LH, et al. Major achievements of evidence-based traditional Chinese medicine in treating major diseases. Biochem Pharmacol (2017) 139:94-104. doi: 10.1016/j. bcp.2017.06.123

63. Dinicolantonio JJ, Lavie CJ, Serebruany VL, O'Keefe JH. Statin wars: the heavyweight match-atorvastatin versus rosuvastatin for the treatment of atherosclerosis, heart failure, and chronic kidney disease. Postgrad Med (2013) 125(1):7-16. doi: 10.3810/pgm.2013.01.2620

64. Seto SW, Au AL, Lam TY, Chim SS, Lee SM, Wan S, et al. Modulation by simvastatin of iberiotoxin-sensitive, Ca2+-activated $\mathrm{K}+$ channels of porcine coronary artery smooth muscle cells. Br J Pharmacol (2007) 151(7):987-97. doi: $10.1038 /$ sj.bjp. 0707327

65. Toth PP. An update on the benefits and risks of rosuvastatin therapy. Postgrad Med (2014) 126(2):7-17. doi: 10.3810/pgm.2014.03.2736

66. Hu Y, Zhou X, Liu P, Wang B, Duan DM, Guo DH. A comparison study of metformin only therapy and metformin combined with Chinese medicine jianyutangkang therapy in patients with type 2 diabetes: A randomized placebo-controlled double-blind study. Complement Ther Med (2016) 24:1318. doi: 10.1016/j.ctim.2015.11.005

67. Zhao Y, Peng R, Zhao W, Liu Q, Guo Y, Zhao S, et al. Zhibitai and lowdose atorvastatin reduce blood lipids and inflammation in patients with coronary artery disease. Medicine (2017) 96(7):e6104. doi: 10.1097/ MD.0000000000006104

68. Ren DD, Li J, Chang B, Li CS, Yang JH. Early intervention with Didang decoction delays macrovascular lesions in diabetic rats through regulating AMP-activated protein kinase signaling pathway. Chin J Nat Med (2017) 15(11):847-54. doi: 10.1016/S1875-5364(18)30018-9

69. Jiang W, Cen Y, Song Y, Li P, Qin R, Liu C, et al. Artesunate attenuated progression of atherosclerosis lesion formation alone or combined with rosuvastatin through inhibition of pro-inflammatory cytokines and proinflammatory chemokines. Phytomedicine (2016) 23(11):1259-66. doi: 10.1016/j.phymed.2016.06.004

70. Wang Z, Tang Z, Zhu W, Ge L, Ge J. Efficacy and safety of traditional Chinese medicine on thromboembolic events in patients with atrial fibrillation: A systematic review and meta-analysis. Complement Ther Med (2017) 32:1-10. doi: 10.1016/j.ctim.2017.03.006
71. Emeto TI, Moxon JV, Au M, Golledge J. Oxidative stress and abdominal aortic aneurysm: potential treatment targets. Clin Sci (2016) 130(5):301-15. doi: $10.1042 /$ CS20150547

72. Emeto TI, Seto SW, Golledge J. Targets for medical therapy to limit abdominal aortic aneurysm progression. Curr Drug Targets (2014) 15(9):860-73. doi: 10. 2174/1389450115666140804155036

73. Maegdefessel L, Dalman RL, Tsao PS. Pathogenesis of abdominal aortic aneurysms: microRNAs, proteases, genetic associations. Annu Rev Med (2014) 65(1):49-62. doi: 10.1146/annurev-med-101712-174206

74. Hance KA, Tataria M, Ziporin SJ, Lee JK, Thompson RW. Monocyte chemotactic activity in human abdominal aortic aneurysms: role of elastin degradation peptides and the $67-\mathrm{kD}$ cell surface elastin receptor. J Vasc Surg (2002) 35(2):254-61. doi: 10.1067/mva.2002.120382

75. Kasashima S, Kawashima A, Zen Y, Ozaki S, Kasashima F, Endo M, et al. Upregulated interleukins (IL-6, IL-10, and IL-13) in immunoglobulin G4-related aortic aneurysm patients. J Vasc Surg (2017). doi: 10.1016/j. jvs.2016.12.140

76. Bartoli MA, Parodi FE, Chu J, Pagano MB, Mao D, Baxter BT, et al. Localized administration of doxycycline suppresses aortic dilatation in an experimental mouse model of abdominal aortic aneurysm. Ann Vasc Surg (2006) 20(2):22836. doi: $10.1007 /$ s10016-006-9017-z

77. Boyle JR, Mcdermott E, Crowther M, Wills AD, Bell PR, Thompson MM. Doxycycline inhibits elastin degradation and reduces metalloproteinase activity in a model of aneurysmal disease. J Vasc Surg (1998) 27(2):354-61. doi: 10.1016/S0741-5214(98)70367-2

78. Manning MW, Cassis LA, Daugherty A. Differential effects of doxycycline, a broad-spectrum matrix metalloproteinase inhibitor, on angiotensin II-induced atherosclerosis and abdominal aortic aneurysms. Arterioscler Thromb Vasc Biol (2003) 23(3):483-8. doi: 10.1161/01. ATV.0000058404.92759.32

79. Petrinec D, Liao S, Holmes DR, Reilly JM, Parks WC, Thompson RW. Doxycycline inhibition of aneurysmal degeneration in an elastase-induced rat model of abdominal aortic aneurysm: preservation of aortic elastin associated with suppressed production of $92 \mathrm{kD}$ gelatinase. J Vasc Surg (1996) 23(2):33646. doi: 10.1016/S0741-5214(96)70279-3

80. Mosorin M, Juvonen J, Biancari F, Satta J, Surcel HM, Leinonen M, et al. Use of doxycycline to decrease the growth rate of abdominal aortic aneurysms: a randomized, double-blind, placebo-controlled pilot study. J Vasc Surg (2001) 34(4):606-10. doi: 10.1067/mva.2001.117891

81. Kalyanasundaram A, Elmore JR, Manazer JR, Golden A, Franklin DP, Galt SW, et al. Simvastatin suppresses experimental aortic aneurysm expansion. J Vasc Surg (2006) 43(1):117-117.e39. doi: 10.1016/j.jvs.2005.08.007

82. Luan Z, Chase AJ, Newby AC. Statins inhibit secretion of metalloproteinases-1, $-2,-3$, and -9 from vascular smooth muscle cells and macrophages. Arterioscler Thromb Vasc Biol (2003) 23(5):769-75. doi: 10.1161/01. ATV.0000068646.76823.AE

83. Nagashima H, Aoka Y, Sakomura Y, Sakuta A, Aomi S, Ishizuka N, et al. A 3-hydroxy-3-methylglutaryl coenzyme A reductase inhibitor, cerivastatin, suppresses production of matrix metalloproteinase- 9 in human abdominal aortic aneurysm wall. J Vasc Surg (2002) 36(1):158-63. doi: 10.1067/ mva.2002.123680

84. Yoshimura K, Nagasawa A, Kudo J, Onoda M, Morikage N, Furutani A, et al. Inhibitory effect of statins on inflammation-related pathways in human abdominal aortic aneurysm tissue. Int J Mol Sci (2015) 16(5):11213-28. doi: 10.3390/ijms 160511213

85. Ding R, Mcguinness CL, Burnand KG, Sullivan E, Smith A. Matrix metalloproteinases in the aneurysm wall of patients treated with low-dose doxycycline. Vascular (2005) 13(5):290-7. doi: 10.1258/rsmvasc.13.5.290

86. Ferguson CD, Clancy P, Bourke B, Walker PJ, Dear A, Buckenham T, et al. Association of statin prescription with small abdominal aortic aneurysm progression. Am Heart J (2010) 159(2):307-13. doi: 10.1016/j.ahj.2009.11.016

87. Kang OH, Chae HS, Choi JG, Oh YC, Lee YS, Kim JH, et al. Ent-pimara-8(14), 15-dien-19-oic acid isolated from the roots of Aralia cordata inhibits induction of inflammatory mediators by blocking NF-kappaB activation and mitogenactivated protein kinase pathways. Eur J Pharmacol (2008) 601(1-3):179-85. doi: 10.1016/j.ejphar.2008.10.012

88. Choi RJ, Shin EM, Jung HA, Choi JS, Kim YS. Inhibitory effects of kaurenoic acid from Aralia continentalis on LPS-induced inflammatory response 
in RAW264.7 macrophages. Phytomedicine (2011) 18(8-9):677-82. doi: 10.1016/j.phymed.2010.11.010

89. Lyu JH, Lee GS, Kim KH, Kim HW, Cho SI, Jeong SI, et al. ent-kaur-16-en-19oic Acid, isolated from the roots of Aralia continentalis, induces activation of Nrf2. J Ethnopharmacol (2011) 137(3):1442-9. doi: 10.1016/j.jep.2011.08.024

90. Cao RY, St Amand T, Li X, Yoon SH, Wang CP, Song H, et al. Prostaglandin receptor EP4 in abdominal aortic aneurysms. Am J Pathol (2012) 181(1):31321. doi: $10.1016 /$ j.ajpath.2012.03.016

91. Ghoshal S, Loftin CD. Cyclooxygenase-2 inhibition attenuates abdominal aortic aneurysm progression in hyperlipidemic mice. PLoS ONE (2012) 7(11):e44369. doi: 10.1371/journal.pone.0044369

92. Liu W, Wang B, Wang T, Liu X, He X, Liu Y, et al. Ursodeoxycholic acid attenuates acute aortic dissection formation in angiotensin II-infused apolipoprotein E-deficient mice associated with reduced ROS and increased Nrf2 levels. Cell Physiol Biochem (2016) 38(4):1391-405. doi: $10.1159 / 000443082$

93. Burtenshaw D, Hakimjavadi R, Redmond EM, Cahill PA. Nox, reactive oxygen species and regulation of vascular cell fate. Antioxidants (2017) 6(4):90. doi: $10.3390 /$ antiox 6040090

94. Lassègue B, San Martín A, Griendling KK. Biochemistry, physiology, and pathophysiology of NADPH oxidases in the cardiovascular system. Circ Res (2012) 110(10):1364-90. doi: 10.1161/CIRCRESAHA.111.243972

95. Muntean DM, Sturza A, Dănilă MD, Borza C, Duicu OM, Mornoș C. The role of mitochondrial reactive oxygen species in cardiovascular injury and protective strategies. Oxid Med Cell Longev (2016) 2016(2016):p. 8254942-. doi: $10.1155 / 2016 / 8254942$

96. Pincemail J, Defraigne JO, Courtois A, Albert A, Cheramy-Bien JP, Sakalihasan N. Abdominal aorta aneurysm (AAA): Is there a role for prevention and therapy using antioxidants? Curr Drug Targets (2017). doi: 10.2174/1389450 118666170918164601

97. Bao W, Morimoto K, Hasegawa T, Sasaki N, Yamashita T, Hirata K, et al. Orally administered dipeptidyl peptidase-4 inhibitor (alogliptin) prevents abdominal aortic aneurysm formation through an antioxidant effect in rats. J Vasc Surg (2014) 59(4):1098-108. doi: 10.1016/j.jvs.2013.04.048

98. Chen Q, Wang Q, Zhu J, Xiao Q, Zhang L. Reactive oxygen species: key regulators in vascular health and diseases. Br J Pharmacol (2017) 172(11 Suppl(). doi: 10.1111/bph.13828

99. Satoh K, Nigro P, Matoba T, O'Dell MR, Cui Z, Shi X, et al. Cyclophilin a enhances vascular oxidative stress and the development of angiotensin II-induced aortic aneurysms. Nat Med (2009) 15(6):649-56. doi: 10.1038/ nm.1958

100. Yu Z, Zhang Y, Liu N, Yuan J, Lin L, Zhuge Q, et al. Roles of neuroglobin binding to mitochondrial complex III subunit cytochrome $\mathrm{cl}$ in oxygenglucose deprivation-induced neurotoxicity in primary neurons. Mol Neurobiol (2016) 53(5):3249-57. doi: 10.1007/s12035-015-9273-4

101. Aivatidi C, Vourliotakis G, Georgopoulos S, Sigala F, Bastounis E, Papalambros E. Oxidative stress during abdominal aortic aneurysm repair-biomarkers and antioxidant's protective effect: a review. Eur Rev Med Pharmacol Sci (2011) 15(3):245-52.

102. Miller FJ, Sharp WJ, Fang X, Oberley LW, Oberley TD, Weintraub NL. Oxidative stress in human abdominal aortic aneurysms: a potential mediator of aneurysmal remodeling. Arterioscler Thromb Vasc Biol (2002) 22(4):560-5. doi: 10.1161/01.ATV.0000013778.72404.30

103. Xiong W, Mactaggart J, Knispel R, Worth J, Zhu Z, Li Y, et al. Inhibition of reactive oxygen species attenuates aneurysm formation in a murine model. Atherosclerosis (2009) 202(1):128-34. doi: 10.1016/j. atherosclerosis.2008.03.029

104. Kigawa Y, Miyazaki T, Lei XF, Nakamachi T, Oguchi T, Kim-Kaneyama JR, et al. NADPH oxidase deficiency exacerbates angiotensin II-induced abdominal aortic aneurysms in mice. Arterioscler Thromb Vasc Biol (2014) 34(11):2413-20. doi: 10.1161/ATVBAHA.114.303086

105. Delbosc S, Diallo D, Dejouvencel T, Lamiral Z, Louedec L, Martin-Ventura JL, et al. Impaired high-density lipoprotein anti-oxidant capacity in human abdominal aortic aneurysm. Cardiovasc Res (2013) 100(2):307-15. doi: $10.1093 / \mathrm{cvr} / \mathrm{cvt} 194$

106. Martin-Ventura JL, Madrigal-Matute J, Martinez-Pinna R, Ramos-Mozo P, Blanco-Colio LM, Moreno JA, et al. Erythrocytes, leukocytes and platelets as a source of oxidative stress in chronic vascular diseases: detoxifying mechanisms and potential therapeutic options. Thromb Haemost (2012) 108(3):435-42. doi: 10.1160/TH12-04-0248

107. Chan E, Wong CY, Wan CW, Kwok CY, Wu JH, Ng KM, et al. Evaluation of anti-oxidant capacity of root of Scutellaria baicalensis Georgi, in comparison with roots of Polygonum multiflorum Thunb and Panax ginseng CA Meyer. Am J Chin Med (2010) 38(4):815-27. doi: 10.1142/S0192415X10008263

108. Wang CZ, Mehendale SR, Yuan CS. Commonly used antioxidant botanicals: active constituents and their potential role in cardiovascular illness. Am J Chin Med (2007) 35(4):543-58. doi: 10.1142/S0192415X07005053

109. Eckert A, Keil U, Kressmann S, Schindowski K, Leutner S, Leutz S, et al. Effects of EGb 761 Ginkgo biloba extract on mitochondrial function and oxidative stress. Pharmacopsychiatry (2003) 36(Suppl 1):S15-23. doi: 10.1055/s-200340449

110. Yuan Q, Wang CW, Shi J, Lin ZX. Effects of Ginkgo biloba on dementia: An overview of systematic reviews. J Ethnopharmacol (2017) 195:1-9. doi: 10.1016/j.jep.2016.12.005

111. Kaneko H, Anzai T, Morisawa M, Kohno T, Nagai T, Anzai A, et al. Resveratrol prevents the development of abdominal aortic aneurysm through attenuation of inflammation, oxidative stress, and neovascularization. Atherosclerosis (2011) 217(2):350-7. doi: 10.1016/j. atherosclerosis.2011.03.042

112. Crowther M, Goodall S, Jones JL, Bell PR, Thompson MM. Localization of matrix metalloproteinase 2 within the aneurysmal and normal aortic wall. $\mathrm{Br}$ J Surg (2000) 87(10):1391-400. doi: 10.1046/j.1365-2168.2000.01554.x

113. Hong HS, Hwang JY, Son SM, Kim YH, Moon M, Inhee MJ. FK506 reduces amyloid plaque burden and induces MMP-9 in A PPP/PS1 double transgenic mice. J Alzheimers Dis (2010) 22(1):97-105. doi: 10.3233/JAD-2010-100261

114. Kadoglou NP, Liapis CD. Matrix metalloproteinases: contribution to pathogenesis, diagnosis, surveillance and treatment of abdominal aortic aneurysms. Curr Med Res Opin (2004) 20(4):419-32. doi: $10.1185 / 030079904125003143$

115. Lv BJ, Lindholt JS, Wang J, Cheng X, Shi GP. Plasma levels of cathepsins $\mathrm{L}, \mathrm{K}$, and $\mathrm{V}$ and risks of abdominal aortic aneurysms: a randomized population-based study. Atherosclerosis (2013) 230(1):100-5. doi: 10.1016/j. atherosclerosis.2013.05.018

116. Carrell TW, Burnand KG, Wells GM, Clements JM, Smith A. Stromelysin-1 (matrix metalloproteinase-3) and tissue inhibitor of metalloproteinase-3 are overexpressed in the wall of abdominal aortic aneurysms. Circulation (2002) 105(4):477-82. doi: 10.1161/hc0402.102621

117. Petersen E, Gineitis A, Wågberg F, Angquist KA. Activity of matrix metalloproteinase-2 and -9 in abdominal aortic aneurysms. Relation to size and rupture. Eur J Vasc Endovasc Surg (2000) 20(5):457-61. doi: 10.1053/ ejvs.2000.1211

118. Wilson WR, Anderton M, Schwalbe EC, Jones JL, Furness PN, Bell PR, et al. Matrix metalloproteinase- 8 and -9 are increased at the site of abdominal aortic aneurysm rupture. Circulation (2006) 113(3):438-45. doi: 10.1161/ CIRCULATIONAHA.105.551572

119. Wilson WR, Schwalbe EC, Jones JL, Bell PR, Thompson MM. Matrix metalloproteinase 8 (neutrophil collagenase) in the pathogenesis of abdominal aortic aneurysm. Br J Surg (2005) 92(7):828-33. doi: 10.1002/ bjs. 4993

120. Longo GM, Xiong W, Greiner TC, Zhao Y, Fiotti N, Baxter BT. Matrix metalloproteinases 2 and 9 work in concert to produce aortic aneurysms. $J$ Clin Invest (2002) 110(5):625-32. doi: 10.1172/JCI0215334

121. Pyo R, Lee JK, Shipley JM, Curci JA, Mao D, Ziporin SJ, et al. Targeted gene disruption of matrix metalloproteinase-9 (gelatinase B) suppresses development of experimental abdominal aortic aneurysms. J Clin Invest (2000) 105(11):1641-9. doi: 10.1172/JCI8931

122. Moran CS, Mccann M, Karan M, Norman P, Ketheesan N, Golledge J. Association of osteoprotegerin with human abdominal aortic aneurysm progression. Circulation (2005) 111(23):3119-25. doi: 10.1161/ CIRCULATIONAHA.104.464727

123. Sun J, Sukhova GK, Zhang J, Chen H, Sjöberg S, Libby P, et al. Cathepsin K deficiency reduces elastase perfusion-induced abdominal aortic aneurysms in mice. Arterioscler Thromb Vasc Biol (2012) 32(1):15-23. doi: 10.1161/ ATVBAHA.111.235002

124. Wang J, Sukhova GK, Liu J, Ozaki K, Lesner A, Libby P, et al. Cathepsin G deficiency reduces periaortic calcium chloride injury-induced abdominal 
aortic aneurysms in mice. J Vasc Surg (2015) 62(6):1615-24. doi: 10.1016/j. jvs.2014.06.004

125. Abraham S, Kumar MS, Sehgal PK, Nitish S, Jayakumar ND. Evaluation of the inhibitory effect of triphala on PMN-type matrix metalloproteinase (MMP9). J Periodontol (2005) 76(4):497-502. doi: 10.1902/jop.2005.76.4.497

126. Kudalkar MD, Nayak A, Bhat KS, Nayak RN. Effect of Azadirachta indica (Neem) and Aloe vera as compared to subantimicrobial dose doxycycline on matrix metalloproteinases (MMP)-2 and MMP-9: An in-vitro study. Ayu (2014) 35(1):85-9. doi: 10.4103/0974-8520.141947

127. Yu YM, Lin HC, Chang WC. Carnosic acid prevents the migration of human aortic smooth muscle cells by inhibiting the activation and expression of matrix metalloproteinase-9. Br J Nutr (2008) 100(4):731-8. doi: 10.1017/ S0007114508923710

128. Yoshimura K, Aoki H, Ikeda Y, Fujii K, Akiyama N, Furutani A, et al. Regression of abdominal aortic aneurysm by inhibition of c-Jun N-terminal kinase. Nat Med (2005) 11(12):1330-8. doi: 10.1038/nm1335

129. Suh SJ, Kwak CH, Chung TW, Park SJ, Cheeeei M, Park SS, et al. Pimaric acid from Aralia cordata has an inhibitory effect on TNF- $\alpha$-induced
MMP-9 production and HASMC migration via down-regulated NF- $\mathrm{kB}$ and AP-1. Chem Biol Interact (2012) 199(2):112-9. doi: 10.1016/j. cbi.2012.06.003

130. Wang L, Wang B, Li H, Lu H, Qiu F, Xiong L, et al. Quercetin, a flavonoid with anti-inflammatory activity, suppresses the development of abdominal aortic aneurysms in mice. Eur J Pharmacol (2012) 690(1-3):133-41. doi: 10.1016/j. ejphar.2012.06.018

Conflict of Interest Statement: The authors declare that the research was conducted in the absence of any commercial or financial relationships that could be construed as a potential conflict of interest.

Copyright $\odot 2018$ Seto, Chang, Kiat, Wang and Bensoussan. This is an open-access article distributed under the terms of the Creative Commons Attribution License (CC BY). The use, distribution or reproduction in other forums is permitted, provided the original author(s) and the copyright owner are credited and that the original publication in this journal is cited, in accordance with accepted academic practice. No use, distribution or reproduction is permitted which does not comply with these terms. 